\title{
A HISTERIA EM A CARNE, DE JULIO RIBEIRO
}

\section{André Luis Masiero}

Mestre e Doutor e Psicologia pela USP - RP. Psicólogo da Pró Reitoria de Assuntos Comunitários e Estudantis - Ufscar. Professor do curso de pós graduação lato sensu em Psicanálise: teoria e clínica da PUC Minas em Poços de Caldas.

\section{Resumo}

Analisa-se no referencial psicanalítico freudiano a obra A carne, de Julio Ribeiro, romance naturalista publicado em 1888. A obra critica a formação dos papéis de gênero na cultura do século XIX e antecipa idéias psicanalíticas sobre sexualidade e histeria, o que permite uma interessante aproximação entre literatura e psicanálise. A análise é focada no desenvolvimento dos dois personagens centrais, Lenita e Manduca. Observou-se na primeira uma transformação da histeria, de desvio para transgressão e daí para a crítica da sexualidade e dos papéis femininos. Já as angústias e conflitos masculinos são marcados pelo silêncio, uma falha discursiva a qual não permite classificações psicopatológicas. Ao final a histérica Lenita fala e interrompe um longo ciclo de repetição compulsiva enquanto Manduca linearmente emudece e sucumbe. Retomando o início da psicanálise observa-se o mesmo fenômeno: a dificuldade, admitida por Freud, em expor a histeria masculina.

Palavras-chave: histeria; psicanálise; literatura.

\section{THE HYSTERIA IN THE FLESH, OF JULIO RIBEIRO}

\begin{abstract}
This paper analyzes the novel The flesh of Julio Ribeiro, from the perspective of freudian psychoanalysis. The book, a naturalistic novel published in 1888 , criticizes the formation of gender roles in nineteenth-century culture and anticipates psychoanalytic ideas about sexuality and hysteria, which allows an interesting approach between literature and psychoanalysis. The analysis is focused on the development of the two central characters, Lenita and Manduca. We observed in Lenita a transformation of hysteria, first it appears like a illness, after to transgression and thence like a critique of sexuality and gender roles. The male anxieties and conflicts are marked by silence, a discursive failure which does not allow psychopathological ratings. At the end the hysteric Lenita interrupts a long cycle of compulsive repetition and Manduca linearly stay mute and succumbs. Returning to the beginning of psychoanalysis observe the same phenomenon: the difficulty, admitted by Freud, in exposing male hysteria.
\end{abstract}

Keywords: hysteria; psychoanalisis; literatura. 


\title{
LA HYSTERIA EN LA CARNE, DE JULIO RIBEIRO
}

\begin{abstract}
Resumen
En este trabajo se analiza la novela A carne Julio Ribeiro a partir de la psicoanalisi freudiana. La novela naturalista, publicada en 1888 critica la formación de los roles de género en la cultura del siglo XIX y se anticipa a las ideas psicoanalíticas acerca de la sexualidad y la histeria, lo que permite un acercamiento interesante entre la literatura y el psicoanálisis. El análisis se centra en el desarrollo de los dos personajes centrales, Lenita y Manduca. Hemos observado en la primera personaje uma transformación de la histeria, de la desviación a la transgresión y de allí a la crítica de la sexualidad y los roles de género. Las ansias y los conflictos masculinos están marcados por el silencio, una hendidura discursiva que no permite clasificaciones psicopatológicas. Al final la histérica Lenita interrumpe un ciclo largo de repetición compulsiva and Manduca de forma lineal permanece mudo y sucumbe. Volviendo a los inicios del psicoanálisis si observa el mismo fenómeno: la dificultad, admitió Freud, en la exposición de la histeria masculina.
\end{abstract}

Palavras clave: histeria; psicoanalisis; literatura.

\section{INTRODUÇÃO}

\section{Literatura e ficção teórica}

Talvez ao se iniciar um trabalho sobre Psicanálise e literatura fosse conveniente esclarecer primeiramente o que não se pretende com ele, e não seus objetivos. Comecemos assim destruindo dois preconceitos comuns nesta aproximação que poderiam levar a um mau entendimento do texto.

Não se pretende com este trabalho fazer da literatura uma fonte de ensinamentos de psicopatologia que confirme ou refute os pressupostos da Psicanálise. Tentar enquadrar clinicamente qualquer obra literária é até possível, mas não ultrapassa uma leitura reducionista que pouco contribui com a aproximação psicanálise e literatura. Personagens e heróis não se prestam a modelos de casos clínicos (como o próprio título deste trabalho pode levar a entender) tampouco se limitam a legar ensinamentos morais para a posteridade.

Um preconceito ainda mais danoso é tentar entender a obra literária como sintoma de conflitos inconscientes do autor. Isto seria tão fácil e convincente quanto anacrônico. Bastaria servir-se dos dados biográficos do autor e pinçar eventos isolados de uma longa vida que supostamente o teriam levado a elaborar seus conflitos interiores através de sua obra, imprimindo nos personagens seu próprio pathos. Fosse assim não existiriam interpretações, leituras, elucidações ou críticas. Para todo o conjunto sintomático haveria uma psicopatologia correspondente, bem como um modelo de interpretação. 
Obviamente o autor tem um papel ativo na elaboração de sua obra e parte de sua criação é extraída de sua realidade fantasiada, na forma de devaneio, ou racionalmente através da observação do cotidiano ou mesmo da ciência, como aparece na literatura naturalista frequentemente. Freud (1996d), no artigo Escritores criativos e devaneios, investigando o processo de criação literária, articula presente, passado e futuro da vida do autor. Uma ocasião motivadora no presente remete a um desejo reprimido do passado, o que vai possibilitar uma reflexão para o futuro, resultando na obra. No processo criativo o desejo já presente de forma latente articula os três tempos. Histórias grandiosas e interessantes todos tem algumas para contar, mas o que os escritores criativos têm de especial não é propriamente o conteúdo de suas criações e sim a capacidade de dar forma ao desejo e eliminar as barreiras com o leitor, ou estimulá-lo a ultrapassá-las despertando um encantamento estético no outro. A existência em si mesma faz de qualquer homem comum um poeta ou escritor em potencial.

Todo o psicanalista, ao ouvir associações livres, relato de sonhos ou angústias participa de uma experiência estética semelhante à criação literária, tanto como autor, quando tenta recriar um registro escrito de sua escuta, quanto como leitor, em suas tentativas de desvendar ou criar algum sentido dos sintomas de seu paciente. Como dizem muitos pacientes "minha vida daria uma novela".

As construções psicanalíticas assemelham-se a narrativa literária, e isto não é novidade desde que Freud foi agraciado com o prêmio Goethe de literatura em 1930. Aliás, Freud sempre foi visto com desconfiança pelas ciências naturais e medicina, no entanto, o afastamento da ciência assumido abertamente pelos primeiros psicanalistas no início do século $X X$ e a aproximação da filosofia e literatura é que permitiu a fundação de um saber original. Como é comum na história da ciência, justamente nos momentos de grandes rupturas epistemológicas é que surgiram os conhecimentos mais interessantes e duradouros, como se na fenda da própria razão emergissem as novas formas de racionalidade. Porém, no momento em que a fenda se abre não é possível dizer se estamos diante de um novo saber ou de misticismo, pseudociência ou puro charlatanismo, epítetos que já foram atribuídos a Psicanálise no início de sua história. O contrário é mais estranho. As maiores tragédias humanas tinham justificativas racionais como suporte ou ainda cientistas de alta credibilidade 
oferecendo variados argumentos e dados para ações que se revelaram em pouco tempo a mais absurda loucura. Machado de Assis no conto O Alienista, já bastante estudado, ou o testemunho O cemitério dos vivos, de Lima Barreto, inserem-se nesta crítica. Talvez, por isso, para sondarmos os limites da razão, é que precisamos tanto da história, da arte e da literatura.

Em Psicanálise o termo narração pode assumir significados diversos, mas se pensarmos no contexto clínico, a construção narrativa sempre será fruto de uma relação. Em última instância surge no par dialógico transferência/contratransferência. Sem isso não existe narrativa clínica, ainda que possa haver narrativa Psicanalítica.

Na obra Notas psicanalíticas sobre um relato autobiográfico de um caso de paranóia, Freud (1996e) analisa Daniel Paul Schreber, "paciente" diagnosticado com dementia paranoides, o qual jamais encontrou. Toda análise foi feita sobre a sua autobiografia Memória de um doente dos nervos (Schereber, 2006), a qual escreveu após algumas internações por problemas psiquiátricos. Para mostrar que havia recuperado a razão, Schreber escreveu suas memórias esperando reassumir seu posto de juiz. Depois de passar por vários manicômios, faleceu em 1910.

Para o psicanalista italiano Antonino Ferro (2000), toda a narrativa clínica é uma co-narrativa, o que não pode existir nesta obra de Freud. Não há dúvidas de que o caso Schreber é uma construção psicanalítica, mas ainda cabe contestar se é uma construção propriamente clínica. Ao analisar um caso exclusivamente através de um testemunho escrito, Freud assume e expõe as dificuldades deste empreendimento. É interessante que as poucas interpretações que faz do "paciente" são, em suas palavras, "apenas tentativas", uma vez que um paranóico como Schreber não se deixaria levar completamente pelo processo analítico, pela sua incapacidade de estabelecer o vínculo transferencial indispensável à análise. Também por isso, diz Freud, concede-se o direito de aventurar-se em uma análise de um texto autobiográfico, tomando-o como uma forma de produção do inconsciente. De qualquer forma Freud estava mais interessado em sondar a experiência humana que eliminar sintomas ou esboçar mais uma psicopatologia geral. A literatura é mais uma dessas experiências, dentre tantas outras. Entendemos aqui experiência não no sentido lockeano, mas, sobretudo, em sua etimologia, "o que ou aquele que foi exposto ao perigo", daí o antepositivo latino peri comum às duas palavras. (Houaiss, 2002). 


\section{MÉTODO}

Do que foi dito até aqui temos de assumir que todo o relato de caso de certa forma é uma criação ficcional a partir de uma experiência, uma vez que o fenômeno clínico é fugaz e temporal, isto é, só pode ser aprisionado no momento mesmo em que ocorre para jamais se repetir novamente. Como uma das formas de produção e transmissão da Psicanálise, o relato de caso é uma tentativa de aprisionar este momento, por isso será sempre incompleto. Freud logo percebeu que a literatura tinha a capacidade de dar voz e revelar um segmento silencioso e estranho do ser humano, o qual chamou de inconsciente. $O$ que pode fazer então o psicanalista em sua escuta e narrativa a não ser literatura? Quando ouve, é um leitor, quando relata, um autor. Aqui reside a originalidade da clínica psicanalítica. Como diz Ferro (2000, p. 33), "contemo-nos histórias para, talvez, nos dizer verdades". Na mesma fenda da racionalidade que dizíamos acima, a criação ficcional vai permitir à clínica psicanalítica constituir algo de verdadeiro e objetivo. Como muito bem expressa Kon (2003) a Psicanálise permite apagar a fronteira entre ficção e teoria, criando algo como uma "ficção teórica". Sem atacar a racionalidade científica, permite-se ultrapassá-la, compondo outro regime de construção de verdades, que depende muito mais da natureza do objeto investigado - o fenômeno anímico - que da vontade do investigador ou de seus pressupostos metodológicos. Nessa construção deve haver espaço para o inesperado e o espontâneo, como em qualquer espaço de criação literária ou artística.

Freud (1996g) nos Estudos sobre a histeria se deu conta de que o anímico não poderia ser aprisionado pelo método das ciências naturais de sua época, quando constatou que os histéricos respondiam melhor à hipnose e sugestão, que aos tratamentos físicos disponíveis, sem contar que os sintomas clínicos observados não se encaixavam nos achados neurológicos de outros cientistas (Masiero, Oliveira, Ragnoli, Gozzoli, 2005). Até aceitava o paralelismo psicofísico, mas não acreditava na descrição mecanicista proposta pela neurofisiologia da época. Algo na relação corpo/alma/mente deveria ser re-descrito, sob outras bases conceituais. Mesmo que se soubesse que necessariamente deveria haver uma excitação cerebral anormal para o desenvolvimento do sintoma histérico, não era possível saber qual a natureza desta excitação desencadeante. 0 inconsciente novamente foi a resposta incompleta de Freud. 
Existem muitas formas de produção de conhecimento em Psicanálise. A rigor pode-se dividir os métodos em dois grandes grupos. Aqueles provenientes das observações propriamente clínicas, isto é, na relação transferencial entre analista e paciente. Aqueles provenientes da observação do cotidiano, das artes, da literatura etc. Freud, como já visto na introdução, utilizou-se dos dois métodos, mas reservou o título de Psicanalista ao primeiro grupo. A clínica é sem dúvida o espaço privilegiado da produção psicanalítica. Não nos perderemos em uma reflexão sobre o significado da palavra método em Psicanálise, o que certamente renderia um novo artigo. Limitamo-nos a afirmar que Psicanalisar é sinônimo de investigar tendo um aparato técnico e conceitual como orientação.

Aqui, primeiramente foi realizada uma leitura atenta da obra em questão, como uma forma de atenção flutuante procurando romper com o limite entre ficção e teoria, como diz Kon (2003). Esse processo é especialmente facilitado quando se trata da literatura de orientação naturalística, pois os autores tomam fatos do cotidiano e das ciências, quase como um cientista e os reelabora em uma história quase documentária. Ultrapassando esse limite procuramos ouvir os personagens em seu contexto. Após esta escuta criamos uma narrativa interpretativa, sobre as bases conceituais da Psicanálise, sobretudo sexualidade histeria, que resultou em nossa interpretação da obra. Segundo Kehl (2007) quando se deseja desvendar novos campos de ação e criação psicanalítica, nada melhor que mergulhar na ficção, seja de um relato de paciente, seja de uma personagem.

\section{RESULTADOS}

\section{A carne: silêncio histérico}

No romance A carne, de Julio Ribeiro (Ribeiro, 1972), os conflitos de seus personagens mostram 0 esteio subjetivo das psicopatologias, dos comportamentos, formas de ser, agir e sofrer, enfim, que denotam a falência moral do fim do século XIX e a necessidade da instalação de outros códigos socioculturais. O romance discute temas controversos como divórcio, família, sexualidade, apontando para uma redefinição dos papéis de gênero, então naturalizados por uma sexologia puritana e higienista, temas intimamente relacionados à definição da histeria. 
Através dos dois personagens centrais da obra, Lenita e Manuel Barbosa evidencia-se uma descrição da histeria muito próxima das concepções psicanalíticas. Embora este paralelo seja bastante conhecido pelo menos em relação à personagem Lenita, com mais sutileza, Julio Ribeiro traz também uma preciosa descrição dos conflitos masculinos através do personagem Manuel Barbosa, o Manduca. Quando comparamos $A$ carne com as poucas descrições de Freud sobre a histeria masculina podemos nos arriscar a ponto de dizer que o personagem encerra uma misteriosa dinâmica histérica. Lenita é de fato reconhecida como histérica durante a obra, mas a Manduca, em nenhum momento é atribuída qualquer categoria psicopatológica.

Vejamos a seguir um pequeno resumo (insuficiente, mas necessário) da obra para nos auxiliar a análise. O romance conta a história de Helena ou Lenita. Filha única, a mãe morrera no parto. A criança sobrevivera graças a uma ama negra que a amamentou. O pai, o Dr. Lopes Matoso encarregou-se da criação da menina concedendo-Ihe uma educação exemplar em ciência, artes e línguas. Já na juventude, dispensava todos os pedidos de casamento, desdenhava dos homens e dizia que não sentia a necessidade de unir-se a ninguém. Apesar de acreditar-se superior, quando sentisse necessidade, casar-se-ia com um homem medíocre pois o talento, segundo acreditava, era herdado de mãe para filho ou de pai para filha. Assim explicava a superioridade de sua inteligência. Aos 22 anos Lenita perde também o pai. Sozinha e com a saúde abalada muda-se para a fazenda do coronel Barbosa no interior de São Paulo. O coronel era um velho conhecido com quem seu pai havia passado a infância e juventude. Embora fosse muito bem tratada pela esposa doente do coronel e pela criadagem, a vida na fazenda era tediosa e solitária. Entregava-se horas a leituras, a contemplação e passeios pela fazenda e redondezas. Começa então a ter crises nervosas, durante as quais apresentava agressividade e desejos extravagantes. Quando se acalmava era tomada por delírios e sonhos de forte conteúdo erótico.

Durante um delírio diante uma reprodução em bronze da estátua Gladiador Borghese, de Agasias, começa a imaginá-la não mais como obra de arte, mas eroticamente, como um homem viril, com um corpo bem conformado, desencadeando assim uma série de pensamentos sexuais. No início sente asco de si mesma por dar-se conta de que estava sujeita aos baixos desejos da carne como qualquer outro animal. Em pouco tempo entrega-se às fantasias sexuais sem culpa, contestando para si mesma as convenções morais hipócritas da 
sociedade diante dos atos da natureza. Em uma das muitas conversas, o coronel fala de seu filho, Manuel Barbosa, de quem Lenita já ouvira falar sem muitos detalhes. Homem culto, quarenta e poucos anos, conhecera muitos países durante os 10 anos em que vivera na Europa. Casado durante dois anos com uma francesa, estava separado e não mais pretendia voltar. Manduca, como era chamado, estava em Paranapanema caçando e pretendia retornar à fazenda em breve. Pela descrição de sua vida e hábitos Lenita o imagina um homem forte e atlético e passa então a ansiar por conhecê-lo, sem esconder suas intenções. Ao mesmo tempo em que ela descobria o gozo sexual tornava-se cruel com os animais e as pessoas que julgava inferiores. Sadicamente beliscava as crianças escravas, quebrava asas de pássaros e adorava presenciar o espancamento de escravos fujões. Gostava da sensação de ter o poder de vida e de morte sobre os escravos e animais. Quando chega Manduca, Lenita decepciona-se com sua aparência. Não tinha o físico que imaginara em suas fantasias eróticas. Mas com o tempo nutrem primeiramente uma amizade, aprofundada pelos interesses intelectuais em comum. Ela então se apaixona por ele depois de salva-la de uma picada de cascavel. Lenita declara seu amor e após uma certa resistência de Manduca, tornam-se amantes. Mantêm o caso em segredo, até que ele tem de partir a negócios para Ipanema para cuidar da compra de um novo engenho para moagem de cana.

Mexendo as coisas do quarto de Manduca, Lenita descobre que havia tido outras amantes, quiçá muitas. Sentindo-se usada por um lado, mas permissiva por outro, entra em um novo conflito e passa a ter novas crises nervosas. Estava grávida. Resolve então partir às pressas para São Paulo, mesmo contra a vontade do coronel Barbosa. Nem mesmo esperou o amante retornar de Ipanema. Depois de um tempo escreve uma carta reveladora contando sua atitude: Não poderia desposar um homem separado, pois nem a lei nem a igreja permitiam o divórcio no Brasil. Não havia alternativa para salvar-se da desonra. Teve então de procurar um pai oficial para o filho que viria. Casaria com o Dr. Mendes Maia, um antigo pretendente bacharel em Direito, que conhecera em um baile em Campinas havia alguns anos, cujo único defeito, segundo o coronel Barbosa, era ser nortista. Depois do casamento em São Paulo, partiriam para a Europa. Desesperado, e impressionado com a ousadia de Lenita, Manduca suicida-se com uma injeção de curare. Ainda consciente, mas já sob efeito implacável do veneno, arrepende-se de seu ato. 


\section{DISCUSSÃO}

\section{Lenita}

A obra gerou grande polêmica principalmente pela solução encontrada por Lenita para salvar sua honra. O parecer do padre português Senna Freitas, com o título jocoso A carniça, publicado em Novembro de 1888 no Diário Mercantil de São Paulo revela sua surpresa:

Não é nada natural que uma donzela honesta, virgem como a supõe o autor, educada esmeradamente por seu pai, estréie em sexualidade erótica pelo meretrício, e tomando por duas vezes a atitude agressiva, própria do homem. Não é nada natural que um blasé do cupidismo como era Manuel Barbosa, se suicidasse simplesmente porque uma de suas muitas ninons lhe voltava as costas e ia casar com um birbante destinado a co-honestar-lhe cientemente o filho futuro de outro pai (Freitas, 1972, p. 186).

Num romance que se dizia naturalista, dedicado ao "mestre" Emile Zola, como poderia uma mulher contradizer seus pendores naturais à maternidade, à castidade e ao comedimento, ainda mais depois de tantas crises histéricas, e mudar-se de cidade grávida de um homem casado e encontrar outro que concordasse em assumir o filho? Impossível. De onde o autor teria tirado inspiração para descrição tão aviltante da fêmea sagrada? Certamente não fora da observação da natureza, segundo Senna Freitas, colocando em suspeita a moral e a sanidade mental de Julio Ribeiro como parte da crítica à sua obra. A natureza, como reflexo da perfeição divina, não permitiria tamanhos desvios de conduta.

Segue-se uma série de trocas de ofensas entre o padre e o autor no mesmo periódico. A resposta de Julio Ribeiro viria numa série de artigos intitulados 0 urubu - Padre Senna Freitas (Ribeiro, 1972), no qual mostra a deficiência dos argumentos do padre, seu pífio conhecimento de ciências naturais, seu autoritarismo inquisitorial, bem como as inúmeras falhas sintáticas de seu texto.

É importante não perdermos de vista a crítica do padre, pois nos será útil como um porta-voz do período, argumentando a partir do real, o outro lado da ficção.

Conforme apontam vários autores (Scotti, 2002; Rouanet, 2004; Patrasso e Grant, 2007), no final do século XIX a histeria foi tema constante na literatura, sobretudo naturalista e realista. Alguns autores como Aluisio Azevedo em $\mathrm{O}$ homem, Gustav Flaubert em Madame Bovary, Eça de Queirós em O primo Basílio, chegaram até mesmo a antecipar com precisão muitas idéias 
psicanalíticas sobre os sonhos, sexualidade e histeria na formulação dos personagens e enredos. Na obra A carne, ao contrário de Magdá, Emma Bovary, Luísa ou tantas outras, mostra um novo tipo de personagem que floresceu no final do século XIX e que fascina ainda hoje, a "femme fatale". Não se trata exatamente de uma vilã, mas é uma personagem que pode assumir várias faces surpreendentes, ora uma justiceira, ora vingativa, mas sempre com razões éticas de sê-lo e que dão suporte às suas atitudes. Na primeira metade da obra o desenvolvimento da personagem Lenita leva a crer que realmente se tratava de uma "histérica clássica", nos moldes que Charcot, Freud e Breuer descreveriam poucos anos depois. Mãe morta no parto, filha única, criada com o pai, excelentes dotes intelectuais, repulsiva ao sexo no comportamento e fala, mas contraditoriamente, na intimidade, plena de desejos e fantasias não realizadas, sonhos e devaneios sexuais. As crises histéricas, evidenciadas por sintomas típicos, parecem estar conduzindo a personagem à ruína final, a morte ou a loucura, como em muitas outras obras do período. Mas eis que nos últimos capítulos encontra uma solução viável para o drama que corrobora detalhes importantes do caráter da personagem, mas passados quase despercebidos durante o enredo.

Apesar de sua revolta nada fizera ativamente para prejudicar Manduca, o "amante infiel". Casando-se com um antigo pretendente, o nortista Dr. Mendes Maia, que a aceitou grávida em troca do seu amor, demonstra o caráter racional e pragmático que se sobrepõe às ameaças da desrazão histérica, que ronda a obra toda e às vezes aparece explicitamente. De doente, a heroína passa a crítica das convenções como o matrimônio e a castidade, que, se por um lado garantem a coesão cultural, por outro podam a própria natureza humana. Lenita recusa-se a pagar este preço. Trata-se de uma discussão típica do século XIX, o conflito homem/natureza, mediado pela moral. Aqui reside mais um aspecto original da obra. A crítica social tão comum na literatura naturalista é feita a partir do ponto de vista exclusivamente feminino e ao final dá voz e razão a uma personagem que julgou histérica. As outras personagens femininas da obra são a própria mãe de Lenita, morta durante o parto e a mãe de Manduca. Entrevada numa cadeira de rodas, não exerce grandes influências no enredo e é tratada com respeito, mas com certa indiferença por todos. A ex-mulher francesa de Manduca é citada duas ou três vezes. Enfim, Lenita é a única mulher falante da obra e o perigo é que talvez fale por todas. 
Insatisfeita em sua condição, a heroína está só. A obra insinua que parte de suas decisões são incitadas pelas suas leituras científicas e literárias. Isso indica que Lenita chegou a um ponto de ruptura e caberá a ela assumir um papel ativo diante de uma feminilidade morta (sua própria mãe), caduca (mãe de Manduca) ou distante (a ex-mulher de Manduca). Em determinados momentos a obra até parece "dessexualizar-se", amainando as tensões entre os personagens. As cenas brutais das caçadas de Manduca e Lenita juntos e em igualdade diante da natureza ou seus estudos e diálogos intelectualizados e assexuados evidenciam algo como períodos de latência na obra, uma zona de conforto em que o enredo pouco se desenvolve. Nestes momentos o autor oferece belas descrições ambientais ao lado de conceitos científicos da medicina e tecnologia. Mas ela sabe que esta planificação sexual é artificial e tampouco corresponde ao seu desejo.

Segundo Nasio (1991) uma das faces da dinâmica histérica é justamente o caráter paradoxal da sexualidade, isto é, uma necessidade sexual excessiva, aqui abertamente assumida por Lenita, e ao mesmo tempo certa repulsa ao sexo. Para o histérico é preferível evitar o contato sexual a ter de deparar-se com uma experiência de forte angústia, pois este contato com o outro é antes de tudo um encontro com a construção da própria sexualidade.

Mais uma vez é Lenita quem tomará o compromisso de encerrar a latência sexual e transformá-la em contato carnal. Como num golpe no amor romântico, Lenita invade o quarto de Manduca e se entrega, sem culpa e determinada a atender aos chamados da natureza. Onde estaria o pecado ao entregar-se a um desejo natural (entenda-se, criado por Deus) passando por cima de convenções criadas artificialmente pelos homens? Neste momento o paradoxo da sexualidade aparecerá com evidência, mas agora envolvendo também o potencial amante. Perplexo com a atitude da mulher ele hesita em consumar o ato, mais uma vez colocando em xeque um valor cultural, o vigor infalível do macho. Manduca parece estar diante de algo completamente novo, embora já conhecesse outras mulheres.

Não tarda para que Lenita se decepcione, pois ficaria grávida de um homem que, embora separado, ainda era formalmente casado, pois o divórcio não era reconhecido no Brasil. Criar um filho sem pai era uma desonra; viver em concubinato com o pai do filho era ilegal e imoral. Parecia não haver solução e 
que a personagem, como tantas outras desonradas, histéricas e atrevidas teria o mesmo destino trágico: a loucura ou a morte.

Nem mesmo ela sabe exatamente a razão de seu próprio desejo, mas não tinha dúvidas de como deveria agir. Deixemos Lenita falar por si mesma:

Ao senhor Manuel Barbosa envio muito saudar.

Ao chegar à fazenda, surpreendeu-se de certo com a minha partida um tanto brusca.

Procurou-Ihe explicação, não achou: nem eu. Lembro-Ihe o que diz Spinoza: 'A nossa ilusão do livre arbítrio vem de ignorarmos os motivos que nos dirigem'. No caso desta minha partida, eu poderia bem crer que tinha livre arbítrio. Demais sou mulher, sou fantasque. Quem vai discutir, explicar caprichos de mulher? (...).

Agora nós: o que mais de perto nos toca...

Estou grávida de três meses mais ou menos.

Preciso de um pai oficial para nosso filho: ora pater est quem instae nuptiae demonstrant.

Se tu fosses livre, fazíamos iustas na igreja as nossas nuptias naturais, e tudo estava pronto. Mas tu és casado, e a lei de divórcio, aqui no Brasil, não permite novo enlace: tive de procurar outro.

'Tive de procurar' é modo de dizer: o outro deparou-se-me, e ofereceu-se-me; eu me limitei a aceitá-lo e ainda impus-lhe condições.

É o dr. Mendes Maia.

Ao chegar aqui, escrevi-lhe para a corte; ele veio imediatamente, tivemos uma conferência larga, eu fui franca, contei-Ihe tudo e... e... e nós nos casamos amanhã, as 5 da madrugada... Pelo trem do Norte que parte as 6 , seguimos para a corte, e da corte para a Europa no primeiro vapor.

Sei que te hás de lembrar sempre de mim, como eu sempre me hei de lembrar de ti: calembour a parte, o que entre nós se passou não se olvida.

Não me guardes rancor. Fomos um para o outro o que podíamos ter sido; nada mais, nada menos.

A criança se for menino chamar-se-á Manuel; se for menina, Manuela. (Ribeiro, 1972, p. 169-75).

Em nenhum momento da carta final Lenita mostra ressentimento ou arrependimento, parecendo acreditar realmente que a solução que encontrou foi a mais sensata. Não há qualquer vestígio em sua fala ou atitudes de que repetirá a mesma infelicidade com o marido. Como uma reação diante das condições que se apresentavam naquele momento, a razão se sobrepôs ao desejo da carne. As cenas das caçadas, o desenvolvimento tecnológico com a construção de ferrovias 
e novas técnicas de produção já apontavam o domínio do homem sobre a natureza selvagem. Aqui se fala agora do domínio do desejo que emana do corpo.

O naturalismo nesta obra pode ser entendido sob dois pontos de vista. Primeiramente como cenário e ambiente onde as ações se passam e os personagens se desenvolvem. Neste ponto a obra é impecavelmente descritiva, com dados científicos precisos relatados com profundidade dramática. Mas é na traição da natureza, como entendida no século XIX, isto é, divina, imutável e determinista é que os personagens se revelam. Neste ponto a obra sonda a natureza humana, profana, inconstante e imprevisível. Daí a crítica do padre Senna Freitas recair exatamente sobre estes pontos.

A histérica, agora não mais como uma personagem passiva, mas como um fenômeno cultural típico do final século XIX, assume o papel de revelar o que estava para ser dito, mas permanecia calado e o que estava para ser vivido, mas repousava inerte. Como aponta Roudinesco (2000) a Psicanálise, ao lado do marxismo, faz parte das filosofias da emancipação e estão na base do surgimento do feminismo, sindicalismo e de tantos outros movimentos culturais. A histérica freudiana não falava apenas de sua patologia, mas também de um papel de feminilidade insuportável.

Agora, já não se trata mais de curar a histérica e o que parecia uma doença grave, nos moldes médicos, vai desaparecendo até o final da obra. É compreensível. Lenita "curou-se" falando e revelando-se através de suas atitudes, até a carta final. O que não pôde dizer ao menos deixou grafado e imortalizado. A solução não é o casamento com o Dr. Mendes Maia, mas não mais silenciar-se passivamente diante do desejo. Assim coloca um fim no ciclo de repetições tanto dentro da própria obra quanto das muitas personagens bovaristas da literatura do período, daí a estranheza da obra.

Desde a Comunicação preliminar, Freud (1996c) já apontava a importância da repetição como um dos componentes da dinâmica histérica. É aqui que, juntamente com Breuer, enuncia a máxima: "a histérica sofre de reminiscências". Numa tentativa desesperada de resolução, o recalcado tende a voltar sob outra roupagem, por isso a diversidade sintomática da histeria, o que faz da histérica personagem constante na literatura da virada do século.

Ao longo do desenvolvimento da Psicanálise, a questão da repetição na neurose vai adquirindo autonomia até transformar-se num conceito fundador, 
por volta de 1920. É a chamada compulsão a repetição. (Freud, 1996f) Em observações clínicas e do cotidiano, notou que tanto seus pacientes quanto pessoas comuns tendiam a repetir situações sofridas do passado, uma contradição absurda se pensarmos na máxima darwinista da preservação da vida a qualquer preço ou no princípio do prazer. Isto é, os comportamentos pouco eficazes para a preservação da vida, em uma concepção evolucionista, deveriam tender ao desaparecimento. Com o conceito de compulsão a repetição mostra-se o contrário, mesmo contrários à preservação da vida, permanecem.

Se entendermos o princípio do prazer como dupla manobra de evitar a dor e procurar prazer, reviver a dor passada constantemente é uma contradição na tendência humana de conservação da vida. Em última instância, portanto, a compulsão a repetição é uma face da pulsão de morte, isto é, uma tendência natural de todo o organismo retornar a um estado inicial de repouso. O caminho de todo organismo realmente é em direção à morte, a descoberta de Freud é que este movimento também está presente no desejo e de vez em quando se manifesta no comportamento humano.

Lenita fugiu de um longo ciclo de repetições justamente num momento de afirmação da vida, isto é, quando descobre a gravidez.

Em psicanálise a maternidade remete à lógica fálica, isto é, como sujeito da falta, castrado, é no filho que a feminilidade se completa. E vemos isso perfeitamente no desenvolver da heroína. Ao completar-se na maternidade transforma-se durante todo o enredo até a solução final, bem longe as convenções moralistas e da fazenda de Manuel Barbosa.

\section{Manduca}

Ninguém ignora quem foi Anna O. e sua importância para a história da Psicanálise, por outro lado, August $P$. é um personagem praticamente desconhecido na obra de Freud, pouco estudado e tratado como um "caso menor". Talvez realmente seja.

A questão da histeria masculina na obra de Freud foi uma das maiores controvérsias no início da Psicanálise. Depois de retornar de Paris em 1886 quando estagiou na Salpêtrière acompanhando os trabalhos de Jean-Martin Charcot, Freud apresentou uma conferência intitulada Sobre a histeria masculina na Sociedade de Medicina de Viena. Este texto foi perdido restando somente algumas resenhas e um comentário em seu Estudo autobiográfico (Freud, 
1996g). A idéia de que a histeria poderia ocorrer em homens era uma novidade na medicina da época e apontava para uma total re-descrição da psicopatologia, não sem muita resistência. Criticado por Meynert, seu professor, o trabalho não foi bem aceito por carecer de exemplos clínicos. Freud então saiu à procura de casos que pudessem comprovar essa tese, aliás, semelhante à de Charcot: a desordem não era exclusiva das mulheres, não se tratava de simulação consciente, e algum trauma deveria estar envolvido na formação sintomática. Com a colaboração de um oftalmologista, o Dr. Königstein, descreveu o caso de August P. no artigo Observação de um caso grave de hemianestesia em um homem histérico. (Freud, 1996a).

Se Anna O. é emblemática como caso princeps da Psicanálise, August P. é marcante como caso de histeria masculina, pois é o único texto dedicado exclusivamente ao tema, embora Freud tenha se limitado a uma descrição superficial dos sintomas físicos, evidenciando muito pouco a psicodinâmica do paciente.

August P., 29 anos, gozava de boa saúde e dedicava-se ao ofício de gravador. Aos oito anos foi atropelado na rua e nos dois anos seguintes teve desmaios sucessivos os quais cessaram. O irmão ameaçou esfaqueá-lo em um desentendimento e depois disso desenvolveu uma série de sintomas, como a própria hemiplegia. Dos poucos sintomas indicados por Freud na descrição do caso, um parecia intrigante. Quando Freud solicitava um movimento específico fazendo-o voltar a atenção para um membro, braço ou perna, o paciente não conseguia realizá-lo plenamente. Parecia que havia um dinamismo comum para homens e mulheres na formação dos sintomas histéricos.

Com o tempo Freud parece não mais se interessar pela diferenciação entre histeria masculina e feminina, ou provar que homens também poderiam desenvolver a psicopatologia. Afastando-se da descrição clássica das psicopatologias, Freud buscará entender os sintomas histéricos a partir dos seus conflitos subjacentes observáveis na história do indivíduo remontando a momentos já aparentemente esquecidos. Se a histeria não é mais completamente determinada biologicamente (nem pela neuroanatomia ou neurofisiologia, nem pela hereditariedade) a questão macho/fêmea perde a força. Assim, a explicação da histeria deveria ser procurada em outros lugares, como na formação de papéis sexuais, na cultura, na subjetividade etc.. De acordo com Freud (1996b): 
A histeria é uma neurose no mais estrito sentido da palavra - quer dizer, não só não foram achadas nessa doença alterações perceptíveis do sistema nervoso, como também não se espera que qualquer aperfeiçoamento das técnicas de anatomia venha a revelar alguma dessas alterações. (p. 67).

Logo Freud descobrirá que a sexualidade exerceria um papel fundamental na etiologia da histeria. Primeiramente desenvolverá a teoria da sedução, na qual o histérico teria necessariamente de ter passado por um trauma real, como um abuso ou mesmo ter presenciado uma cena sexual constrangedora, que permanecendo inconsciente desde a infância retornaria posteriormente na forma de sintoma. No entanto, com o aprimoramento da teoria, passa a chamada teoria da fantasia. Não apenas traumas reais poderiam desencadear sintomas histéricos, mas também fantasias dos mais variados tipos que invadiam a consciência colocando-a em conflito.

A construção dos papéis de masculinidade e feminilidade foi um dos assuntos a que Freud se dedicou intensamente. É verdade que considerava a construção dos papéis femininos muito mais complexos que os masculinos.

Se retomarmos a crítica do padre Senna Freitas logo acima veremos que a idéia da definição de papéis de gênero no final do século XIX passava exclusivamente pelo biológico, como exemplo da perfeição da criação divina. Isto oferecia suporte à idéia de que existiam patologias próprias de mulheres, notadamente a histeria, e de homens. Aqui tem-se uma série de lacunas.

O suicídio de Manduca foi um ato ensandecido motivado por outras questões que não somente a desilusão amorosa, razões as quais o enredo deixa somente vestígios. O que significa sua vida solitária? O que o levou a abandonar uma vida confortável ao lado de uma mulher interessante em Paris para enfiarse numa fazenda no interior de São Paulo? Por que hesitou em tomar Lenita como amante enquanto ela própria parecia decidida? Não seria natural que, sendo o macho, consumasse o ato imediatamente? Eram questões que também Lenita se colocava e que a obra não responde. Se a personagem Lenita não deixa lacunas em sua fala e atitudes, o mesmo não ocorre com Manduca. 0 personagem deixa uma sucessão de dúvidas sobre seus desejos e atitudes o que o torna mais enigmático que a própria histérica. A obra aponta para uma série de questionamentos aos pilares da cultura como a sexualidade, casamento, fé e razão etc. e também uma descrição das neuroses e fragilidades masculinas diante de uma incipiente reorganização dos papéis de gênero no final do século 
XIX. O próprio pai de Manduca, o coronel Manuel Barbosa, não encontra um qualificativo para o filho: trata-se de um "esquisitão". Há uma definição de histeria e muito pode ser dito sobre ela, mas o que pode-se dizer sobre "esquisitão" ? Não se trata de um conceito, mas evidencia a lacuna no discurso sobre o universo masculino, pois sequer há uma palavra para qualificar a angústia do personagem.

A crítica literária, levada pela inércia da crítica ao machismo, racismo e misoginia parece deixar em segundo plano a questão da reorganização da masculinidade no final do século XIX. O silêncio diante da angústia masculina num momento de grandes transformações culturais, políticas e éticas, podemos dizer, foi muito maior que aquele diante da reestruturação da feminilidade neste período.

Enquanto podemos ver a tentativa de Lenita em lidar com os pontos de ruptura e as faltas (a morte do pai e da mãe, a necessidade sexual, o tédio etc.) procurando uma ação integradora no desejo, que se não a fizesse feliz a traria de volta a vida, Manduca prefere silenciar-se até o seu inesperado final. De fato ele não tinha outra saída. Não havia o que nem como dizer de sua angústia, pois sequer havia um suporte lingüístico para tal. O fim de Lenita é imortalizado numa carta, já o suicídio de Manduca necessita de um narrador onisciente para relatar seu arrependimento, diante da morte iminente. Trata-se aqui de uma lacuna discursiva sobre a masculinidade, daí a dificuldade mesmo de Freud em encontrar uma casuística clínica para a comprovação da tese da histeria masculina.

Oh, pensava Barbosa, não poder eu ditar a alguém o que em mim se está passando, descrever o gosto desta morte gradual, em que a vida esvai-se como um liquido que se escoa. Que sou eu neste momento? Uma inteligência que sente e quer, presa em um invólucro morto, cativa em um bloco inerte... (Ribeiro, 1972, p. 178).

Sob efeito de curare, veneno que paralisa primeiramente as funções motoras e depois as mentais, quer voltar a vida e reencontrar um sentido ao lado dos pais idosos e necessitados de sua presença. Sem saberem que o filho havia se envenenado, resta-Ihes lamentar. O veneno simboliza bem a separação entre o desejo, ainda presente, e a ação. Sequer no momento da morte, Manduca consegue refletir sobre o que teria se passado. Ele sente e quer, como diz, mas em vida não sabe o que nem como, ou seja, não há um objeto para o desejo e assim morre aos poucos e em silêncio. 
O mesmo silêncio vemos em August P., que, ao contrário de Anna O., é mudo. É Freud quem descreve seus sintomas como observador onisciente e fala pelo paciente.

\section{REFERÊNCIAS}

Assis, J. M. M. (2007). O alienista, in Costa F M. (2007), Os melhores contos de loucura. Rio de Janeiro: Ediouro. (Original publicado em 1881).

Barreto, L. (2007). Cemitério dos vivos, in Costa F M. (2007), Os melhores contos de loucura. Rio de Janeiro: Ediouro. (Original publicado em 1920).

Ferro, A. (2000). A psicanálise como literatura e terapia. Rio de Janeiro: Imago.

Freitas, S. (1972). A carniça, in: Ribeiro, J. (1972) A carne. São Paulo: Editora Três. (Original publicado em 1888)

Freud, S. (1996a). Edição Standard Brasileira das obras completas de S. Freud, Observação de um caso grave de hemianestesia em um homem histérico, v. I, p. 49-57. Rio de Janeiro: Imago. (Original publicado em 1886)

Freud, S. (1996b). Edição Standard Brasileira das obras completas de S. Freud, Ed. Imago Histeria, v. I, p.65-83. Rio de Janeiro: Imago. (Original publicado em 1888)

Freud, S. (1996c). Edição Standard Brasileira das obras completas de S. Freud, Comunicação preliminar, v. I, p. 165-174. Rio de Janeiro: Imago. (Original publicado em 1893)

Freud, S. (1996d). Edição Standard Brasileira das obras completas de S. Freud, Escritores criativos e devaneios, v. IX, p. 149-162. Rio de Janeiro: Imago. (Original plublicado em 1907).

Freud, S. (1996e). Edição Standard Brasileira das obras completas de S. Freud, Notas psicanalíticas sobre um relato autobiográfico de um caso de paranóia (Dementia paranoides), v. XII, p. 23-104. Rio de Janeiro: Imago. (Original publicado em 1911)

Freud, S. (1996f). Edição Standard Brasileira das obras completas de S. Freud, Além do princípio do prazer, v. XVIII, p. 13-85. Rio de Janeiro: Imago. (Original publicado em 1920)

Freud, S. (1996g). Edição Standard Brasileira das obras completas de S. Freud, Um estudo autobiográfico, v. XX, p.11-92. Rio de Janeiro: Imago. (Original publicado em 1925). 
Houaiss, A (2002). Dicionário eletrônico da língua portuguesa. Rio de Janeiro: Objetiva.

Kon, N. M. (2003). A viagem: Da literatura a psicanálise. São Paulo: Cia das Letras.

Kehl, M. R. ( 2007). Bovarismo e modernidade. Revista Literatura e Sociedade, USP, FFCLH, 10, 224-236.

Masiero, A L; Ragnoli, F. A.; Gozzoli, L.; Oliveira, A. L. M. (2006) A crítica freudiana ao reducionismo biológico. Psicologia: Ciência e Profissão, 26(1), 58-69.

Nasio J. D. (1991). A histeria: Teoria clínica e psicanalítica. Rio de Janeiro: Jorge Zahar Editor

Patrasso R. e Grant W. H. (2007). O feminino, a literatura e a sexuação. Psicologia clínica, 19(2), 133-151.

Ribeiro, J. (1972). A carne. São Paulo: Editora Três. (Original publicado em 1888).

Ribeiro, J. (1972). O urubu - Senna Freitas, in Ribiero, J. (1888/1972) A carne. São Paulo: Editora Três. (Original publicado em 1888)

Rouanet, S. P. (2004). A construção da histeria em Aluísio Azevedo. Psicologia Clínica, 16(1), 97-113.

Roudinesco, E (2000). Por que a psicanálise? Rio de Janeiro: Jorge Zahar.

Schreber, D. P. (2006). Memória de um doente dos nervos. Rio de Janeiro: Paz e Terra.

Scotti, S (2002). A histeria em Freud e Flaubert. Estudos de Psicologia, 7(2), 333-341.

Contato: masiero@yahoo.com

Recebido em: 05/08/2012

Revisado em: 14/11/2012

Aceito em: 24/11/2012 